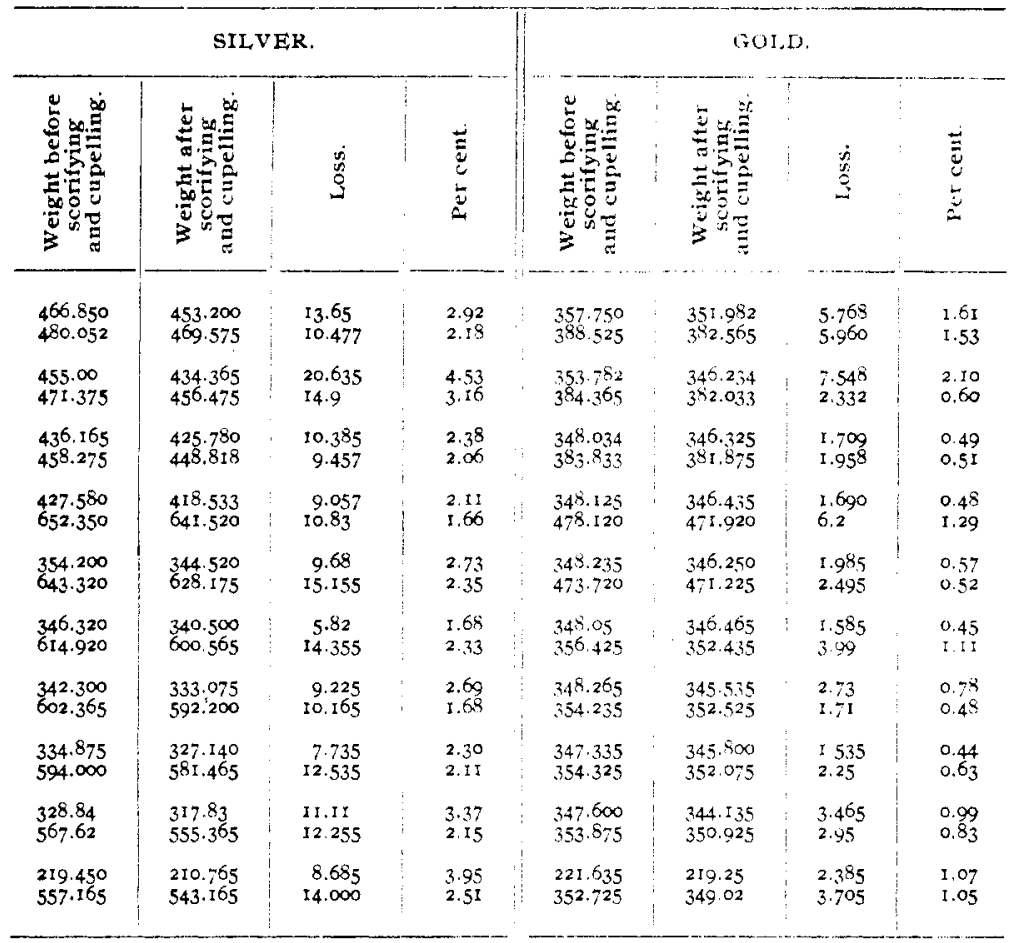

Average percentage loss.....2.54 per cent.

Average percentage loss... 0.87 percent.

Rensselaer Polytechnic Institute, 1893 .

\title{
ON THE SPEED OF REDUCTION OF FERRIC CHLORIDE BY STANNOUS CHLORIDE.
}

BY LOCIS KAHLENBERG.

Received February 8, 1894 .

$T_{\mathrm{HE} \text { reaction that takes place when ferric chloride is treated }}$ with stannous chloride in aqueous solution is expressed by the following equation:

$$
\mathrm{Fe}_{2} \mathrm{Cl}_{6}+\mathrm{SnCl}_{2}=2 \mathrm{FeCl}_{2}+\mathrm{SnCl}_{4} \text {. }
$$

This reaction goes on slowly enough at ordinary temperatures to admit of study from the standpoint of chemical dynamics. It was my purpose to investigate whether the reaction proceeds 
in accordance with the law of mass action, as stated by Guldberg and Waage, ${ }^{1}$ and how the speed of the reaction is affected by the presence of varying quantities of free hydrochloric acid.

Outline of Method of Experimentation.-Solutions of ferric chloride and stannous chloride of known strength were prepared. These were brought to a definite temperature by allowing them to stand in a bath. They were then quickly mixed (in equivalent proportions), and the mixture was kept at the same temperature in an atmosphere of carbon dioxide. At convenient times, samples were taken out with a pipette; these were quickly run into an excess of a saturated solution of mercuric chloride, which, by converting the unchanged stannous chloride into stannic chloride, according to the equation, $\mathrm{SnCl}_{2}+2 \mathrm{HgCl}_{2}=$ $\mathrm{SnCl}_{4}+2 \mathrm{HgCl}$, checked the reaction. The amount of ferrous chloride formed was then determined by means of a standard solution of potassium bichromate. In this process, the bichromate was added until a drop of the mixture on a white porcelain plate showed no longer a blue coloration when brought into contact with a drop of a dilute, freshly prepared solution of potassium ferricyanide.

Preparation of Solutions. - A decinormal solution of potassium bichromate was prepared by taking 4.913 grams of the pure salt to a liter. Its strength was verified by comparison with both ferrous ammonium sulphate and iron wire. $17.85 \mathrm{cc}$. of this solution will change 0 . I gram of iron from the ferrous to the ferric state.

The ferric chloride used was of Merck's manufacture (C. P.). It was tested for arsenic and for sulphuric, nitric, and free hydrochloric acid, and found pure. Four liters of ferric chloride solution were prepared. The strength of this solution was determined by means of the decinormal bichromate solution, after previous reduction at a boiling heat with a slight excess of stannous chloride, and addition of an excess of mercuric chloride before titrating." It was found that twenty-five cc. of the ferric chloride solution were equivalent to twenty-eight $\mathrm{cc}$. of the bichromate.

1 Etudes sur les affinités chimiques, 10, Christiania, I867; also J.prakt, Chem., [2], I9, 69.

2 Kessler, Pogg, Ann., 95, 223-225; also Ztschr, anal. Chem., I1, 249. 
Banca tin was used in preparing the solution of stannous chloride. The tin was found to be free from lead, iron, and arsenic. 30.5 srams of tin, to which a few scraps of platinum har been aclech, were heated with $25 \mathrm{cc}$. of hydrochloric acid of sp. crr. I. I 7 in a flask in an atmosphere of carbon dioxide until nearly all the tin was clissolved. The heating had to be continued for ahout six hours. A little distilled water, previously boiled, was added from time to time so as to keep the rolume of the liquid at about Ioo cc. When the chemical action had ceased, about four to five grams of tin still remained undissolved. The excess of hydrochloric acid was driven off by boiling the liquid down to a small bulk. The stannous chloride thus obtained was ciluted to $4,000 \mathrm{cc}$. with water previously boiled and cooled in an atmosphere of carbon dioxide. That the free hydrochloric acid had been driven off was evident from the fact that a precipitate of stannous oxychloride formed by diluting to this volume. It was found necessary to add to the four liters twenty ce, of hydrochloric acid, of sp. gr. I.I 7 , to bring this precipitate into solution. After this addition of acid and thorough shaking there still remained a faint opalescence, showing that a minimm quantity of acid had been used. The solution thus prepared was at once transferred to a number of flasks holding from 225 to $250 \mathrm{cc}$. about the quantity required for each series of experiments. The flasks were completely filled with the liquicl, then tightly corked and kept in the dark. In this way the stannous chloricle solution could be kept for weeks without changing, and the required quantity could be taken for use without exposing the remainder to the oxidizing influence of the air. The strength of the stannous chloride solution was determined as follows: Twenty-five cc. of the ferric chloride were acidified with hydrochloric acid and heated to boiling, twenty cc. of the stannous chloride were then quickly added and the amount of ferrous chloride formed at once estimated with the decinormal bichromate solution. In this way it was found that twenty cc. of the stannous chloride would reduce $18.7 \mathrm{cc}$. of the ferric chloride.

A saturated solution of mercuric chloride was also prepared. Experimental Details. - In each of the six series of experiments 
conducted, $200 \mathrm{cc}$. of the solution of stannous chloride and 187 cc. of the ferric chloride solution were used. The volume of this mixture was made up to $425 \mathrm{cc}$. for each series. In series I this was done by adding thirty-eight cc. of water, while in series II to VI, five, ten, fifteen, twenty, and twenty-five cc. of hydrochloric acid, of $\mathrm{sp}$. gr. I.I 7 , at $20^{\circ} \mathrm{C}$. respectively were added, together with an amount of water sufficient to make the volume up to $425 \mathrm{cc}$.

Preliminary experiments had shown that the speed of the reaction is greatly increased by raising the temperature and by increasing the amount of free hydrochloric acid present. The experiments were eonsequently carried out at $0^{\circ} \mathrm{C}$., in order that the reaction might go on slowly enough to admit of the study of the increase of the speed of the reaction by the presence of the anounts of free hydrochloric acid above mentioned.

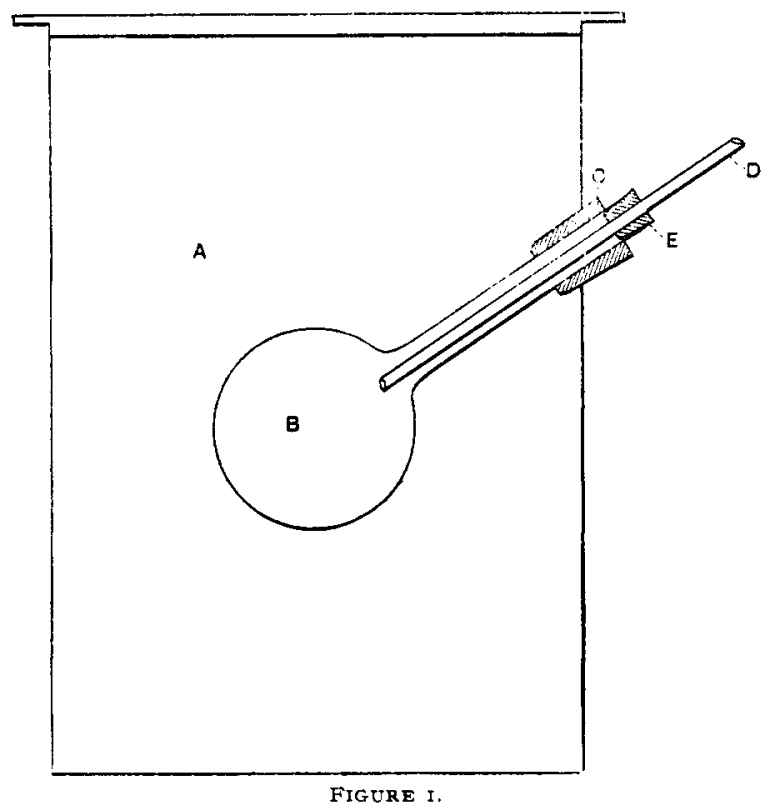

Fig. I shows the apparatus in which the mixture of stannous chloride and ferric chloride was kept at $0^{\circ} \mathrm{C}$. and in an atmosphere of carbon dioxide. The outer vessel $\mathrm{A}$ is made of tin and 
has a capacity of about sixteen liters. It is provided with a wooden jacket and cover. The flask $B$ has a capacity of about $500 \mathrm{cc}$. It is held in position by the tightly fitting: rubber cork $\mathrm{C}$ which fits closely into the spout with which $A$ is provided. The cork $\mathrm{E}$ fits loosely into the neck of the flask. The tube $\mathrm{D}$ is connected with a carbon dioxide generator.

At the beginning of each series of experiments, A was completely filled with melting ice and the air in the flask displaced by carbon dioxide. In the meantime the $200 \mathrm{cc}$. stannous chloride solution and the $187 \mathrm{cc}$. of ferric chloride solution, plus the thirty-eight $\mathrm{cc}$. water-or water plus acid-were cooling in separate flasks in a bath of melting ice. When the solutions had been cooled to $o^{\circ} \mathrm{C}$., they were quickly mixed and poured into the flask B, Fig. I, the cork E being at once replaced. Samples of twenty-five $c c$. each were then taken out with a pipette from time to time, the cork $E$ being slightly raised for the moment so that the pipette could be introduced into the flask B. These samples were quickly run into Erlenmeyer flasks containing fifteen $c c$. of the saturated mercuric chloride solution. The ferrous chloride formed was then estimated by means of the decinormal solution of potassium bichromate, the end of the reaction being judged as above stated. The results of the six series of experiments are given below.

Presentation of Results.- In accordance with the law of Guldberg and Waage, the speed of the reduction of ferric chloride by stannous chloride, when the substances are present in equivalent proportions, is to be expressed by the following equation:

$$
\frac{\mathrm{dx}}{\mathrm{dt}}=\mathrm{c}(\mathrm{a}-\mathrm{x})^{2} \text {, }
$$

in which a represents the amount of substance present at the outset, $x$, the amount of substance changed during the time, $t$, and $c$, a constant depending on the concentration, temperature, etc. From the above equation we have by integration:

$$
\frac{\mathrm{I}}{\mathrm{a}-\mathrm{x}}=\mathrm{ct}+\mathrm{K} \text {. }
$$

Determining $\mathrm{K}$ from the fact that $\mathrm{x}$ is zero when $\mathrm{t}$ is zero, and substituting its value in (2), we have after easy transformation, 


$$
\frac{r}{t} \frac{x}{a-x}=a c \text {. }
$$

The condition then that must be fulfilled, if the reaction follow the law, is that ac be constant.

The results of the six series of experiments are given in tabular form. Under $t$ is given the time in minutes, counted, in the case of series $I$ to $V$, from ten minutes after mixing the substances; while in series VI, five minutes after mixing was taken as the zero point from which to count the time. In the second column are given the amounts of the decinormal bichromate solution used in estimating the ferrous chloride formed. In series I the results of the titrations of two independent series of experiments are given under $\mathrm{I}$ and 2 , while the average is given under 3. The last three columns of each series give the values of $x, \frac{x}{a-x}$, and ac, respectively.

For purposes of comparison, the results given in series I to VI have also been charted in the form of curves-Fig. 2. The abscissae represent the time in minutes, counting from the time of mixing, and the ordinates represent the amounts of ferric chloride reduced in percentages of the total amount present at the beginning. The numbers of the curves correspond to the numbers of the series.

SERIES I. (No free $\mathrm{HCl}$ present.)

\begin{tabular}{|c|c|c|c|c|c|}
\hline \multirow[t]{2}{*}{ (minutes.) } & \multicolumn{2}{|c|}{$\begin{array}{c}\mathrm{K}_{2} \mathrm{Cr}_{2} \mathrm{O}_{7} \\
(\mathrm{ccc} .)\end{array}$} & \multirow[t]{2}{*}{$x$} & \multirow[t]{2}{*}{$\frac{x}{a-x}$} & \multirow[t]{2}{*}{ ac. } \\
\hline & 2 & 3 & & & \\
\hline $0 \ldots \ldots \ldots$ I.3 & $\mathrm{I} .25$ & 1.27 & $\cdots$ & $\cdots \cdots$ & $\cdots \cdots$ \\
\hline $10 \ldots \ldots \ldots 2.1$ & 2.3 & 2.2 & 0.93 & 0.0921 & 0.00921 \\
\hline $20 \ldots \ldots \ldots 2.9$ & 2.8 & 2.85 & 1.58 & 0.1672 & 0.00836 \\
\hline $40 \ldots \ldots \cdot 3.7$ & 3.7 & 3.7 & 2.43 & 0.2825 & 0.00706 \\
\hline $60 \ldots \ldots \ldots 4.2$ & 4.2 & 4.2 & 2.93 & 0.3617 & 0.00603 \\
\hline $80 \ldots \ldots \ldots 4.8$ & 4.6 & 4.7 & 3.43 & 0.4513 & 0.00564 \\
\hline $100 \ldots \ldots \cdot 5.25$ & 5.2 & 5.23 & 3.96 & $0.560 \mathrm{I}$ & 0.00560 \\
\hline $120 \ldots \ldots \ldots .6$ & 5.6 & 5.6 & 4.33 & 0.6462 & 0.00539 \\
\hline $140 \ldots \ldots .6 .0$ & 6.0 & 6.0 & $4 \cdot 73$ & 0.7508 & 0.00536 \\
\hline Igo. . . . . 6.6 & 6.4 & 6.5 & 5.23 & 0.9017 & 0.00475 \\
\hline $250 \ldots \ldots \ldots 7.25$ & $7 \cdot 3$ & 7.27 & 6.00 & I. 1928 & 0.00477 \\
\hline $320 \cdots \cdots \cdots 7.6$ & 7.6 & $\begin{array}{l}7.6 \\
(a=\end{array}$ & $\begin{array}{l}6.33 \\
3)\end{array}$ & 1.3468 & 0.00421 \\
\hline
\end{tabular}


SERIFS II. (Five Cc. $\mathrm{HCl}$ present.)

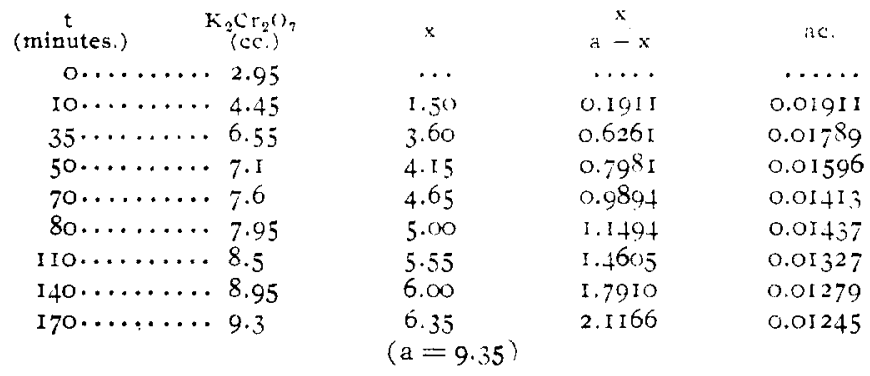

Series III. (Ten cc. free $\mathrm{HCl}$ present.)

\begin{tabular}{|c|c|c|c|}
\hline$\stackrel{t}{\stackrel{t}{(m i n u t e s .)}}$ & $\mathrm{x}$ & $\frac{x}{a-x}$ & ac. \\
\hline $0 \ldots \ldots \ldots 5.55$ & .. & $\cdots \cdots$ & $\ldots$. \\
\hline $10 \ldots \ldots \ldots 7.1$ & 1.55 & $0.298 \mathrm{I}$ & $0.029^{8}$ \\
\hline $20 \ldots \ldots \ldots 7.95$ & 2.40 & 0.5517 & 0.0276 \\
\hline $30 \ldots \ldots \ldots 8.5$ & 2.95 & 0.7763 & 0.0259 \\
\hline $40 \ldots \ldots \ldots 8.95$ & 3.40 & 1.0149 & 0.0254 \\
\hline $50 \ldots \ldots \ldots 9.2$ & 3.65 & $1.177^{8}$ & 0.0236 \\
\hline $70 \ldots \ldots \ldots 9.65$ & 4.10 & I. 5094 & 0.0216 \\
\hline $100 \ldots \ldots \ldots 9.95$ & 4.40 & 5.8734 & 0.0187 \\
\hline $120 \ldots \ldots \ldots 10.15$ & 4.60 & 2.1394 & $0.017^{8}$ \\
\hline $150 \ldots \ldots \ldots 10.45$ & $\begin{array}{l}4.90 \\
a=6.75)\end{array}$ & 2.6487 & 0.0177 \\
\hline
\end{tabular}

SERIES IV. (Fifteen cc. free $\mathrm{HCl}$ present.)

\begin{tabular}{|c|c|c|c|c|}
\hline (minutes.) & $\begin{array}{c}\mathrm{K}_{2} \mathrm{Cr}_{2} \mathrm{O}_{7} \\
(\mathrm{cc}) \text { ) }\end{array}$ & $\mathrm{x}$ & $\frac{x}{a-x}$ & ace. \\
\hline $0 \ldots \ldots .$. & 7.1 & $\ldots$ & $\ldots$ & $\ldots \ldots$ \\
\hline $10 \ldots \ldots \ldots$ & 8.5 & 1.4 & 0.368 & 0.0368 \\
\hline $20 \ldots \ldots \ldots$ & 9.25 & 2.15 & 0.705 & $0.035^{2}$ \\
\hline $30 \ldots \ldots$ & 9.7 & 2.6 & 1.000 & 0.0333 \\
\hline $40 \ldots \ldots \ldots$ & 10.05 & 2.95 & I. 3 I I & 0.0328 \\
\hline $50 \ldots \ldots \ldots$ & 10.35 & 3.25 & 1.667 & 0.0333 \\
\hline $70 \ldots \ldots \ldots$ & 10.6 & $3 \cdot 5$ & 2.059 & 0.0292 \\
\hline $80 \ldots \ldots \ldots$ & 10.75 & 3.65 & 2.355 & 0.0294 \\
\hline $90 \ldots \ldots \ldots$ & 10.85 & $(\mathrm{a}=$ & $2.5^{86}$ & 0.0287 \\
\hline
\end{tabular}

SERIES V. (Twenty cc. free $\mathrm{HCl}$ present.)

\begin{tabular}{|c|c|c|c|c|}
\hline (minutes.) & $\begin{array}{c}\mathrm{K}_{2} \mathrm{Cr}_{2} \mathrm{O}_{7} \\
(\mathrm{cc} .)\end{array}$ & $\mathrm{x}$ & $\frac{x}{a-x}$ & ac. \\
\hline $0 \ldots \ldots \ldots$ & $7 \cdot 55$ & $\cdots$ & $\cdots$ & $\ldots \ldots$ \\
\hline ro......... & 9.15 & 1.6 & 0.508 & 0.0508 \\
\hline $2 I \ldots \ldots \ldots$ & 9.95 & 2.4 & $1.02 I$ & 0.0486 \\
\hline $50 \ldots \ldots \ldots$ & 10.8 & 3.25 & 2.167 & 0.0433 \\
\hline $70 \ldots \ldots$ & II.I & 3.55 & $2.95^{8}$ & 0.0423 \\
\hline $95 \ldots \ldots \ldots$ & I 1.35 & $\begin{array}{c}3.8 \\
(a=4.75)\end{array}$ & 4.000 & 0.0421 \\
\hline
\end{tabular}


SERIES VI. (Twenty-five cc. free $\mathrm{HCl}$ present.)

\begin{tabular}{|c|c|c|c|c|}
\hline (minutes.) & $\begin{array}{c}\mathrm{K}_{2} \mathrm{Cr}_{2} \mathrm{O}_{7} \\
(\mathrm{cc})\end{array}$ & $\mathbf{x}$ & $\frac{x}{a-x}$ & ac. \\
\hline $0 \ldots . . .$. & 7.05 & $\cdots$ & $\ldots$ & $\ldots \ldots$ \\
\hline Io........ & 9.25 & 2.2 & 0.721 & $0.072 \mathrm{I}$ \\
\hline $20 \ldots \ldots \ldots$ & 10.15 & 3.1 & 1.442 & 0.0721 \\
\hline $25 \ldots \ldots \ldots$ & 10.40 & 3.35 & 1.763 & 0.0705 \\
\hline $35 \ldots \ldots \ldots$ & 10.75 & 3.7 & 2.387 & 0.0682 \\
\hline $50 \ldots \ldots$. & I I .0O & $3 \cdot 95$ & 3.038 & 0.0608 \\
\hline $70 \ldots \ldots$ & I I. 25 & 4.2 & 4.000 & $0.057 \mathrm{I}$ \\
\hline $100 \ldots . .$. & I I . 45 & 4.4 & $5 \cdot 176$ & 0.0518 \\
\hline $130 \ldots \ldots \ldots$ & II .55 & $\stackrel{4.5}{(a=5.25)}$ & $6.08 \mathrm{I}$ & 0.0468 \\
\hline
\end{tabular}

It will be noticed that the quantity ac, instead of being constant, decreases in each series. In eight preliminary series of experiments, performed at $0^{\circ}$ and at $15^{\circ}$ to $16^{\circ}$, the same regular decrease of ac was noted. The cause of this retardation of the speed of the reaction has not been further investigated. It seems probable that it is due to the accumulation of the products of the reaction (stannic chloride and ferrous chloride), and to the change in the rate of diffusion as the solution becomes more dilute. It must be observed, however, that while the first values of ac in each of the six series given above are too high, owing probably to disturbing influences at the beginning of the experiments, the values at about the middle of the series vary but slightly indeed, in many instances the differences fall within the limit of error of experimentation. The results above given are sufficient to show that the reaction follows the law of Guldberg and Waage fairly well.

The effect of the presence of varying quantities of free hydrochloric acid on the speed of the reaction can best be seen by comparing the curves in Fig. 2. All the curves show that the reaction goes on must rapidly during the first ten to fifteen minutes after mixing. ${ }^{1}$ During the first forty minutes after mixing, the second five cc. hydrochloric acid (curve III) increases the amount of ferric chloride reduced in about the same degree as does the first five cc. (curve II); but this effect diminishes relatively as the time increases. In general, the curves show that as the amount of free hydrochloric acid is increased the effect on

1 This effect has in part been elininated in preparing the tables above, by choosing ten minutes after mixing as the zero point from which to count the time. 


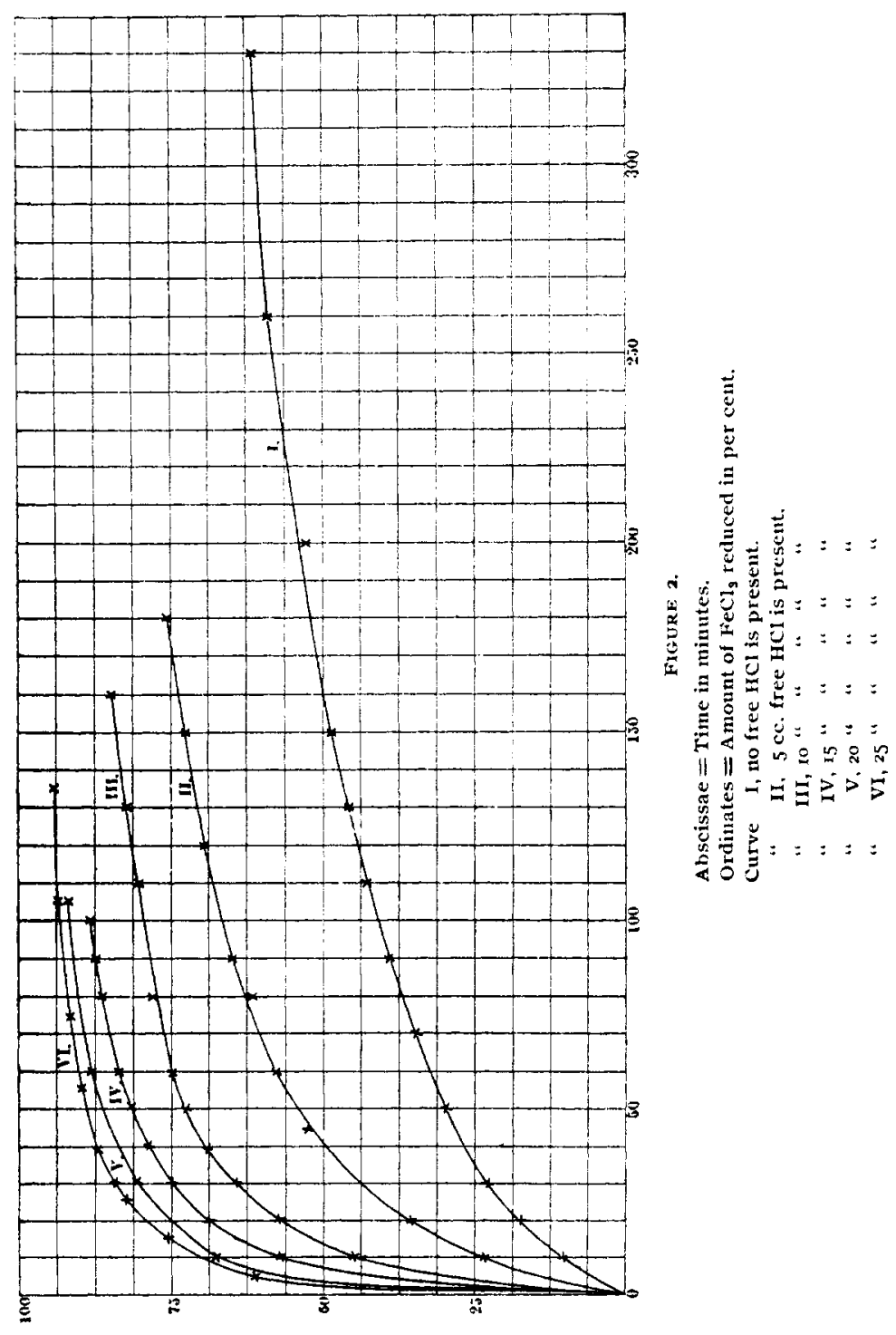


amount of ferric chloride reduced is relatively diminished.

Curves similar to those in Fig. 2 have lately been obtained by Seubert and Dorrer' in the case of the action of ferric chloride on potassium iodide. Their curves show the effect of the presence of an excess of either substance on the speed of the reaction.

In the case of the reduction of ferric chloride by stannous chloride, the part played by the free hydrochloric acid cannot be expressed in the form of a chemical equation; and as there can be no doubt that the amount of free acid present at the end of the reaction is the same as at the beginning, the action of the acid is catalytic in its nature. In the course of his investigations of processes of oxidation and reduction, Prof. Ostwald ${ }^{2}$ has formulated the law that the speed of all processes of oxidation and reduction is increased by the presence of free acids in proportion to their affinity coefficients. He has shown that this law holds also in cases of catalytic action. It would be of interest in this connection to know the effect of the presence of equivalent quantities of other acids on the speed of the reduction of ferric chloride by stannous chloride; but as another problem required my immediate attention, the work could not be continued in this direction.

My thanks are due to Prof. W. W. Daniells for occasional helpful suggestions during the progress of the above experiments.

ChEMTCAL LABORATORY OF THE UNIVERSITY OF WISCONSIN.

\section{THE CHEMICAL AND PHYSICAL EXAMINATION OF PORTLAND CEMENT.}

(Continued from Page 286.)

BY Thomas B. StILlMax, PH.D.

REFERENCES ( 1870 to 1892 ).

I875.

Proceedings of the Institution of Civil Engineers.-Experiments on Portland cement used, in the Portsmouth Dock Yard, 41, 125. Gauging of cement for the test bricks, 126. Degree of fineness to be obserred in grinding, I26. Effect of coarse grinding, 127. Quality of cement not always superior on account of greater weight, 127. Result of inclosing cement in casks or bags after grinding, 128. Average strength of Portland

1 Ztschr, anorg. Chem, , 5, 348 and $352,1893$.

2 Ztschr. phys. Chem., 2, 127. 